American Journal of Anatomy and Physiology
(ISSN:2637-4714)

\title{
The Possible Effects of Asiatic Herbs in SARS-COV-2 and their Mechanism of Action
}

\author{
Ferro M., Graubard A., Ledezma R., Escalante P., Channan G., Dotres V. and Bencomo Y. \\ Department of Sciences, Nutrition Formulators Inc., Miramar, FI, USA.
}

\section{ABSTRACT}

In 2019, a new virus called Severe Acute Respiratory Syndrome Coronavirus 2 (SARS-CoV-2) gave rise to an unknown outbreak that spread in China's Hubei province, triggering a new epidemic known as coronavirus-19 (COVID -19). Several studies have demonstrated the metabolic pathways of SARS-COV-2 in angiotensin-converting enzyme receptors 2 (ACE2). With this, others have been considering an approach with drugs that bind to ACE2 receptors as well as antiviral activity as a possible treatment option for the disease. Thus, the objective of this present review was to evaluate some Asiatic herbs for both the prevention and treatment of COVID-19. Some herbs, such as the extract of Artemisia annua (Artemisinins) and the extract of Isatis

indigotica (Emodin), showed to be effective as inhibitors of adhesion of some viruses. Some studies observed this in the SARS-CoV S / ACE -2 protein interaction in which it inhibited the adhesion of the virus to the cell surface. Similarly, Glycyrrhiza glabra extract (Licorice) showed significant inhibiting action on the influenza virus and was shown to be an effective antiviral in many other viruses by weakening virus activity, such as inhibiting virus gene expression and replication, reducing adhesion force and stress through the reduction of high-mobility-group box 1 (HMGB1) binding to DNA. Additionally, one of the best herbs in effective concentration value (EC50) found in this study was Lycoris Radiata with EC50: 2,4 $\pm 0.2 \mu \mathrm{g} / \mathrm{ml}$. The results presented in this review are promising in the search for prophylactic treatment in a viral pandemic such as SARS-VOC-2. However, Keywords: SARS-COV-2; ACE2; COVID-19; Asiatic Herbs

*Correspondence to Author: Marcelo Ferro

Department of Sciences Nutrition FormulatorsInc., 10407 N Commerce, Parkway, Miramar, FI $33025 \mathrm{Mi}-$ ramar, FI, USA.

How to cite this article:

Ferro M., Graubard A., Ledezma R., Escalante P., Channan G., Dotres V and Bencomo Y.. The Possible Effects of Asiatic Herbs in SARSCOV-2 and their Mechanism of Action.American Journal of Anatomy and Physiology, 2021; 4:15. more clinical trials to validate the processes of the effectiveness of both plants and their extracts, as well as the synergy between the plants themselves are needed to validate future herbal treatments against SARS-VOC-2. 


\section{Introduction}

In 2019, a novel coronavirus named Severe Acute Respiratory Syndrome Coronavirus 2 (SARS-CoV-2) with unknown origin spread in the Hubei province of China [1]. The epidemic disease caused by SARS-CoV-2, also known as coronavirus disease-19 (COVID-19) [2]. The medical community understands that COVID-19 triggers an inflammatory reaction in the human body in response to the virus that is worse than the virus itself ${ }^{[3]}$. This has led some people to experience severe symptoms and in cases has led to deaths ${ }^{[4]}$. Many studies are being carried out in several countries to discover antiviral drugs to combat COVID-19 [5]. Currently, despite the collaborative efforts of governments, researchers, and the pharmaceutical industry, there are no substantially significant treatment protocols for the disease ${ }^{[3]}$.

Understanding the metabolic pathway of SARS-CoV

Several studies have demonstrated the metabolic pathways of SARS-COV-2 in angiotensin-converting enzyme receptors 2 (ACE2) (Fig. 1) ${ }^{[6,7]}$. ACE2 acts as a host cell receptor for SARS-CoV [8]. Binding to ACE2 stimulates clathrin-dependent endocytosis of ACE2 and SARS-CoV, which is essential for viral infection to occur ${ }^{[7]}$. The ACE2 decrease in the cell surface, causing an increase in angiotensin II, consequently causing an activation in the angiotensin II type-1 receptor that triggers severe complications to the lung tissue ${ }^{[9]}$. Many studies have been considering an approach with drugs that bind to ACE2 receptors as a possible treatment option ${ }^{[7]}$.

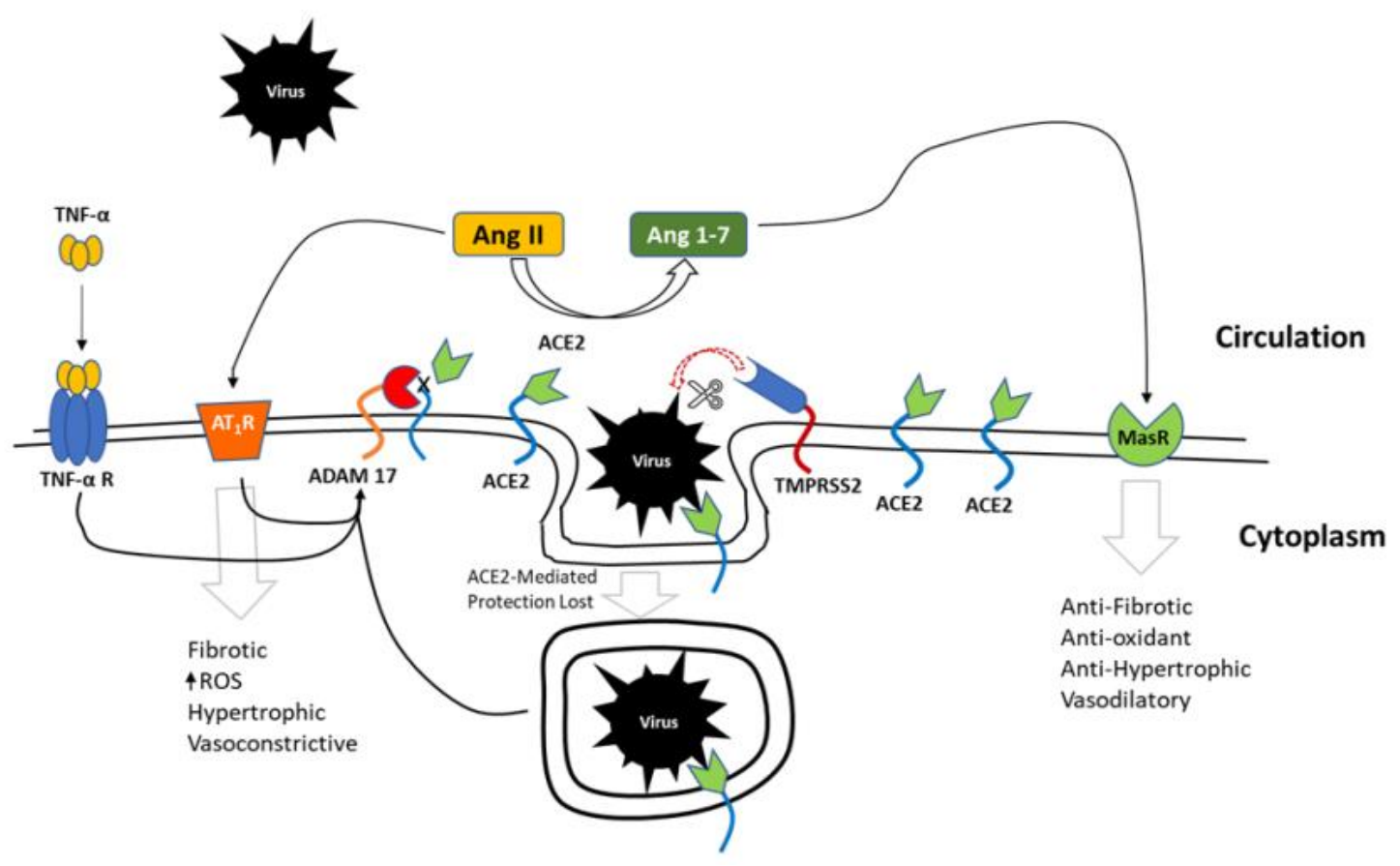

Figure 1 TNF- $\alpha$ : Tumor Necroses Factor alfa; TNF- $\alpha$ R: Tumor Necroses Factor alfa receptor; AT1R: Angiotensin II type 1 receptor; ADAM17: ADAM metallopeptidase domain 17; ACE2: Angiotensin-converting enzyme 2; TMPRSS2: Transmembrane protease, serine 2; Ang II: Angiotensin II; Ang 1-7: Angiotensin 1-7.

Furthermore, researchers have reported the causes COVID-19 [10]. need for urgency in understanding the Spike Protein in SARS-COV-2 pathogenesis of severe acute respiratory Clinical studies have shown that the spike syndrome produced by SARS-CoV-2, which protein SARS-CoV-2 (S) binds to ACE2 and 
together with host proteases, mainly transmembrane serine protease 2 (TMPRSS2), promotes cell entry for the virus ${ }^{[11]}$. In severe acute respiratory syndrome, the spike protein is one of the main structural proteins observed in this process ${ }^{[12]}$. It is essential for the interaction of the virus with host cell receptors and subsequent fusion of the viral envelope with the host cell membrane to allow infection [13]. The spike (S) protein of coronaviruses is one of the proteins responsible for viral entry into target cells ${ }^{[12]}$. The adhesion and entry of the virus into the cells depend on the attachment of the surface unit, $\mathrm{S} 1$, of the protein $\mathrm{S}$ to a cell receptor, which facilitates the attachment of the virus to the surface of the target cells [14]. In addition, entry requires $S$ protein priming by cellular proteases, which entails $S$ protein cleavage at the S1/S2 and the S2 site and allows fusion of viral and cellular membranes, a process driven by the S2 subunit (Fig. 2) ${ }^{[12,14]}$. According to Li et al. (2003), SARS-S engages angiotensinconverting enzyme 2 (ACE2) as the entry receptor ${ }^{[15]}$. Through this, it employs the cellular serine protease TMPRSS2 for S protein priming (Fig. 2) ${ }^{[16]}$.

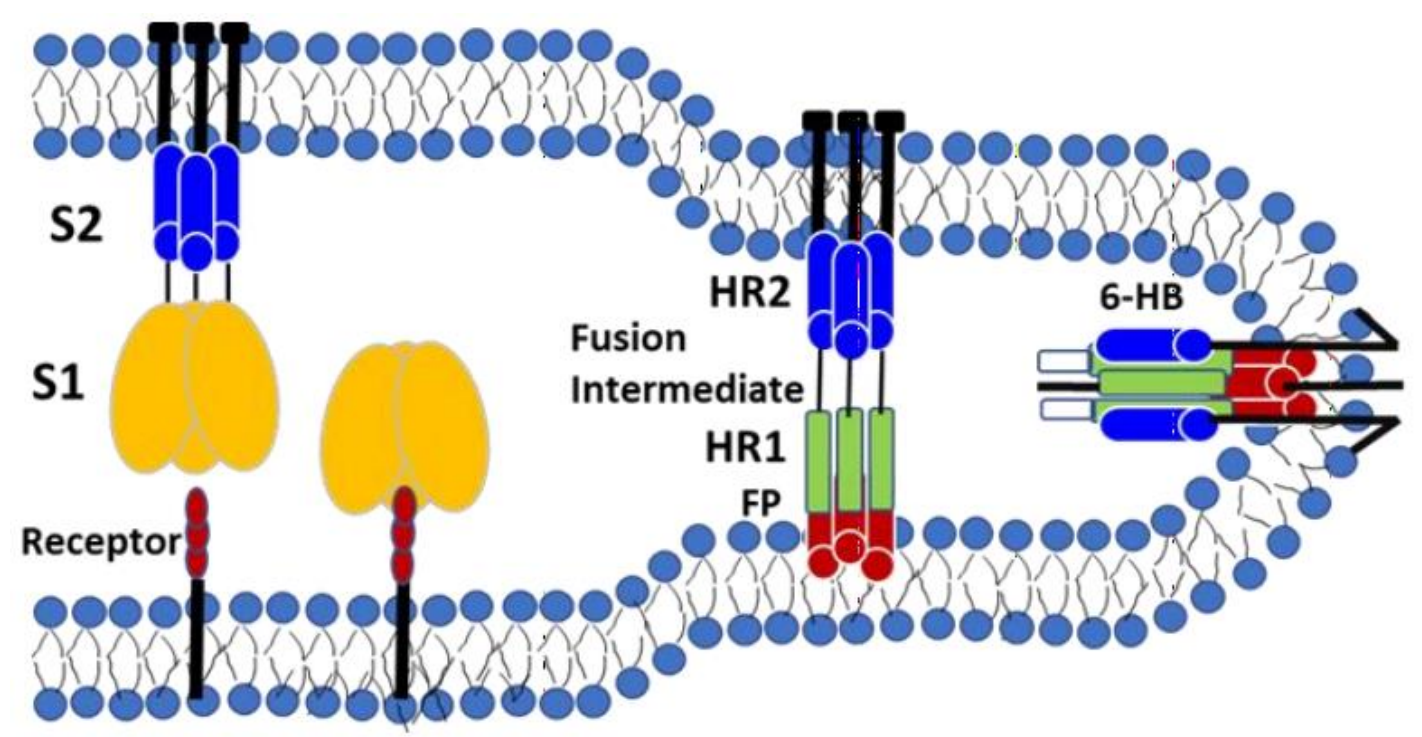

Figure 2 S1 and S2: SARS-COV-2 Skype protein; HR1 and HR2: Heptad Repeat 1 and 2; 6-HB: Six-helix bundle

Transmembrane serine protease 2 (TMPRSS2)

Several studies have sought to understand how SARS-2-S facilitates viral entry into target cells and how this process can be blocked. According to Hoffman et al. (2020), the study result provided evidence that the entry of SARS-CoV2 into the host cell depends on the SARS-CoV ACE2 receptor and can be blocked by a clinically proven inhibitor of the cellular serine protease TMPRSS2 employed by SARS-CoV-2 for S protein initiation (Fig. 3) ${ }^{[14]}$. Although SARS$\mathrm{CoV} 2$ in the lung mainly infects pneumocytes and macrophages [17], ACE2 expression is not limited to the lung, as extrapulmonary spread of SARS-CoV has been observed in ACE2+ tissues ${ }^{[18,14,19]}$. Although the affinity of SARS-S and SARS-2-S for ACE2 has yet to be compared, the same can be expected for SARS-CoV-2 in relation to host cell adhesion ${ }^{[14]}$. In light of the potential increase in the transmissibility of SARS-CoV-2 in relation to SARS-CoV, it can be speculated that the new virus may exploit factors promoting cell-binding more efficiently than SARS-CoV to guarantee a robust infection of cells ACE2 + in the upper respiratory tract ${ }^{[14]}$. 


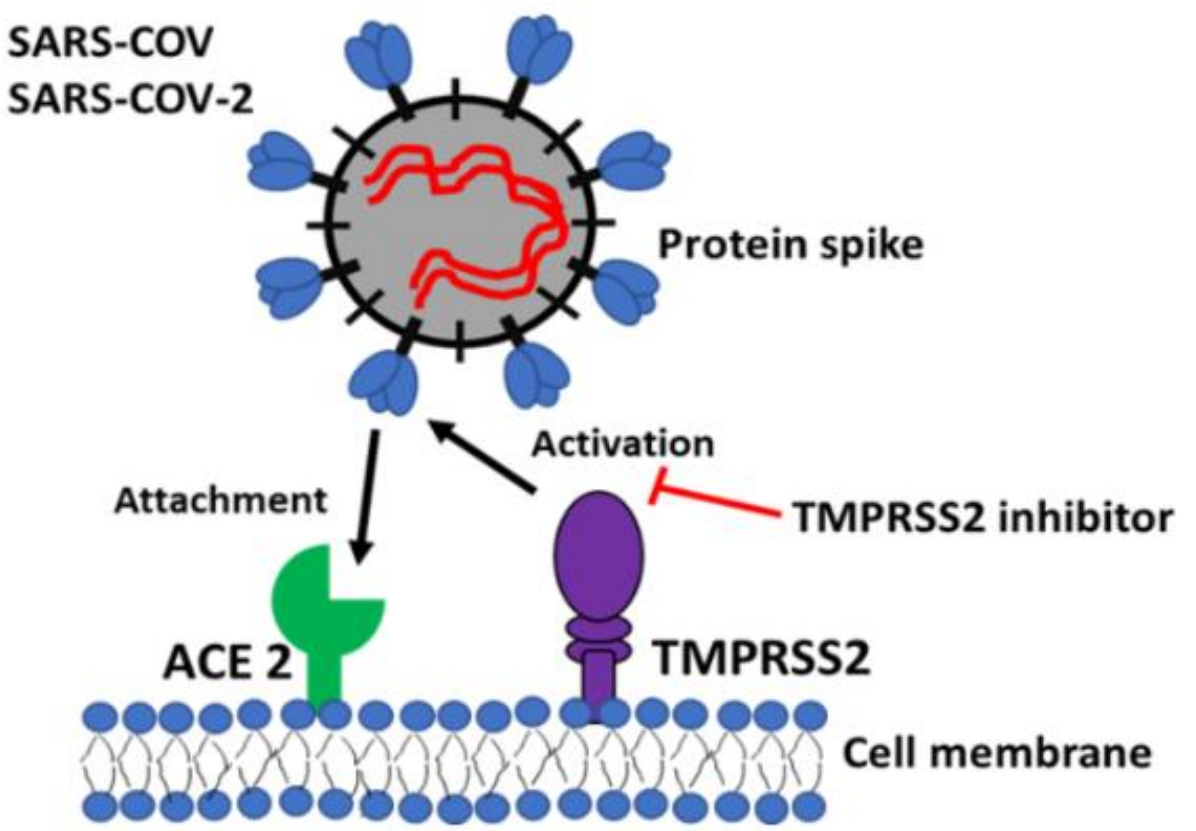

Figure 3 ACE2: Angiotensin-converting enzyme 2; TMPRSS2: Transmembrane protease, serine 2

In view of the need to test new drugs that prevent the anion of SARS-COV-2 on the surface of the host cell, Cheong et al. (2020) reported in their studies that artemisinins derivate extract of the plant Artemisia annua could act on ACE2 receptors ${ }^{[20]}$. Several studies have reported that strategies to block receptors so that SARS-COV2 does not adhere to ACE2 would be a great way to control the SARS-COV-2 pandemic [21]. Further studies are needed to verify the possible mechanisms of action of these plants in the metabolism of ACE2, as we can see below [20]. Several studies have highlighted the role of Traditional Chinese Medicine in treating patients with SARS-CoV-2 ${ }^{[22]}$. However, these comprehensive studies are not available in countries with a solid background in the use of medicinal plants for the treatment of broad-spectrum diseases ${ }^{21]}$. China has an excellent track record in using traditional plant-based formulations for successfully treating SARS coronavirus (SARSCoV) in the Guangdong Province between 2002 through mid-2003 [23]. However, although the precise information on the nature and composition of these plants and their mode of action is not available, their secondary metabolites have been attracting the attention of the scientific community as these metabolites have to impact bioactive properties to control viral replication ${ }^{[24]}$.

India is another country that depended predominantly on herbal medicines under different domain names such as Ayurveda, Siddha and Unani ${ }^{[21]}$. According to researchers, although the advent of allopathic medicines has decreased the prevalence of herbal treatments, the current pandemic emphasizes the need to review these plants and study them using advanced tools and approaches ${ }^{[25]}$. Innovative research is required to dissect the medicinal value of plants to identify suitable phytocomposites that can serve as possible molecules in the treatment of SARS-CoV-2 [21].

Following are the herbals we have identified as having the most promising possibilities to be used in phyto-therapies in the treatment of SARS-COV and SARS-CoV-2.

\section{Licorice (Glycyrrhiza glabra)}

Glycyrrhiza glabra (Fabaceae family), commonly known as licorice, is a perennial herbaceous 
plant that has been used as a medicinal plant for thousands of years ${ }^{[26]}$. Licorice contains more than 20 triterpenoids and nearly 300 flavonoids, among them glycyrrhizin, the major compound isolated from the roots of licorice ${ }^{[27]}$. In view of the need to know the bioactive mechanisms of plants, some studies on antiviral activity have been described by researchers; Cinati et al. (2003) reported that glycyrrhizin is effective against SARS-CoV by inhibiting its viral replication ${ }^{[28]}$. As the structural similarities and comparable modes of replication between SARSCoV and SARS-CoV-2 are very similar, Glycyrrhiza glabra may also be effective in

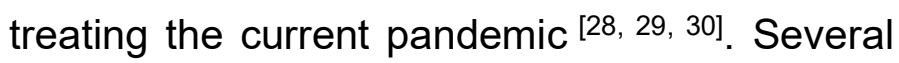

studies have demonstrated that glycyrrhizin showed a significant inhibiting action on the influenza virus as well as an effective antiviral compound against hepatitis C virus (HCV) [31], human immunodeficiency virus (HIV) [32], coxsackievirus B3 (CVB3) [33], duck hepatitis virus (DHV) ${ }^{[34]}$, enterovirus 71 (EV71) [35], coxsackievirus A16 (CVA16) ${ }^{[35]}$, herpes simplex virus (HSV) ${ }^{[36]}$ and highly pathogenic Asian avian influenza $A(\mathrm{H} 5 \mathrm{~N} 1)^{[37]}$ by weakening virus activity, such as inhibiting virus gene expression and replication, reducing adhesion force and stress, and reducing high-mobility-group box1 (HMGB1) binding to DNA ${ }^{[38]}$.

Table 1 - Some drugs in COVID-19 treatment.

\begin{tabular}{|c|c|c|c|}
\hline S. no. & Name of drug & Illnesses treated & References \\
\hline 1 & Chloroquine & Malaria and avian influenza $A$ & Yan et al., 2013 \\
\hline 2 & Remidesivir & Ebola, SARS COV and MERS.COV. & Warren et al., 2016 \\
\hline 3 & Lopinavir/Ritonavir & COVID-19, SARS, MERS and HIV & Wu et al., 2020 \\
\hline 4 & Ribavirin & Hepatitis C & Elfiky, 2020 \\
\hline 5 & Favipiravir & COVID.19 & Wu et al., 2020 \\
\hline 6 & Acyclovir & $\begin{array}{l}\text { SARS, MERS, Coronavirus } 229 \mathrm{E} \text { and } \\
\text { COVID-19 }\end{array}$ & Peters et al., 2015 \\
\hline 7 & $\begin{array}{l}\text { TMPRSS2 inhibitor Camostat } \\
\text { mesylate }\end{array}$ & $\begin{array}{l}\text { SARS, MERS, Coronavirus } 229 \mathrm{E} \text { and } \\
\text { COVID. } 19\end{array}$ & Hoffmann et al., 2020 \\
\hline 8 & Nitazoxanide & SARS, MERS and Influenza & Rossignol, 2016 \\
\hline 9 & Darunavir & COVID-19 & Lin et al, 2020 \\
\hline 10 & $\alpha$-Interferon & $\begin{array}{c}\text { Spectrum of respiratory infections, } \\
\text { RSV and SARS }\end{array}$ & Guerrero et al., 2013 \\
\hline 11 & Carfilzomib & COVID-19 & Wang, 2020 \\
\hline 12 & Oseltamivir & Covio-19 & $\mathrm{Lu}, 2020$ \\
\hline 13 & Azrudine & COVID-19 & Hu et al., 2020 \\
\hline 14 & RNA-dependent RNA polymerase & SARS & Imbert et al., 2006; \\
\hline
\end{tabular}




\section{Myricetin}

Myricetin is a very common phenolic compound in red fruits, vegetables as well as in teas and wines produced from various plants. It occurs in free and glycosidically bound forms, which include myricetin-3-O- (3 " -acetyl) -a-Iarabinopyranide, myricetin-3-O- (4" -acetyl) - $\alpha-$ larabinopyranide, myricetin-

3-O- $\alpha-1-$ ramnopyranoside, myricetin-3-O- $\beta-\alpha-$ galactopyranoside, myricetin-3-O- (6 " -galloyl) $\beta$-d-galactopyranoside, myricetin-3-O - $\beta-d \quad$ xylopyranoside, myricetin $3-\mathrm{O}-\alpha-1-$ arabinofuranoside [39] myricetin-3-O- (2 "-Ogalloyl) -a-I-ramnoside and myricetin-3-O- (3" O- galloyl) - $\alpha$-l-ramnoside and myricetin-3-O- $\alpha-$ I-ramnoside ${ }^{[40]}$. In a study on chemical inhibitors of the SARS coronavirus helicase, $\mathrm{Yu}$ et al. examined the inhibitory effects of 64 purified natural compounds against the activity of SARS helicase, nonstructural protein 13 (nsP13) and the hepatitis $\mathrm{C}$ virus (HCV) helicase, nonstructural protein helicase (NS3h), leading to DNA unfolding double-stranded (ds) based on fluorescence resonance energy transfer (FRET) or using an ATP hydrolysis assay based on colorimetry ${ }^{[41]}$. Although none of the compounds examined in the study inhibited the unwinding activity of DNA or the ATPase activity of the human HCV helicase protein, it was found that myricetin potently inhibits the SARS-CoV helicase protein in vitro, affecting the activity of ATPase, but not the unwinding activity, nsP13 [41]. In addition, it was observed that myricetin did not exhibit cytotoxicity against normal MCF10A breast epithelial cells. The study demonstrated that selected natural flavonoids, including myricetin, can serve as chemical inhibitors of SARS-CoV [42].

\section{Quinine (Cinchona officinalis)}

Another plant extract that caught the attention of the scientific community was quinine. Quinine is an alkaloid obtained from the bark of Cinchona officinalis and has been used in the treatment of malaria for at least 60 years [43]. Chloroquine (CQN) and hydroxychloroquine (HCQN) are considered structural analogs of quinine, and in SARS-CoV-2, hydroxychloroquine in combination with azithromycin is considered more effective in reducing viral loads ${ }^{[44]}$. On the other hand, studies have shown that virus production in Vero B4 cells (a linage of cell used in cell culture), was analyzed by Western blot. The Western blot method was used to study to separates the blood protein and detects the specific protein as antibody. These studies compare quinine activity against SARS-CoV-2 to the activity of $\mathrm{H}-\mathrm{CQN}$ or CQN. The results proved quinine exert a stronger antiviral activity than H-CQN and CQN against SARS-COV-2 [45]. This fluorescence and time-lapse analysis of SARS-CoV-2-mNeonGreen infected Caco-2 cells can confirm a similar quinine-like antiviral effect on a human-derived cell line, revealing that the antiviral effect appears to be specific, since in Vero cells quinine impacted cell viability at a concentration approximately 50 times greater, while the therapeutic window of $\mathrm{H}-\mathrm{CQN}$ and CQN was approximately ten times smaller [45]. These studies affirmed that with no toxic effect observed in quinine indicated that quinine would have the potential for a well-tolerated and widely used treatment option for SARSCoV-2 infections, with a predictable toxicological profile and significantly better when compared to $\mathrm{H}$ CQN or CQN ${ }^{[45]}$.

\section{Amentoflavone (Torreya nucifera)}

Several other plant actives have demonstrated antiviral activities, among them the flavones amentoflavone and some others such as quercetin, luteolin, and apigenin, obtained from Torreya nucifera that inhibited the 3C-like proteinase (3CLpro) function [46]. Torreya 
nucifera is a Taxaceae tree found in snowy areas near the Sea of Jeju Island in Korea that has been used in traditional Asian medicine as a remedy for stomach pain, hemorrhoids, and rheumatoid arthritis, has been chosen as the raw material by virtue of observation 3CLpro inhibition ${ }^{[46]}$. Studies isolated 12 phytochemicals - eight diterpenoids and four bioflavonoids - with inhibitory activity SARS-CoV 3CLpro from the ethanolic extracts of the leaves of the plant, and from the isolated compounds, the amentoflavone bioflavonoid was identified as a potent SARS-CoV 3CLpro inhibitor [47]. In an infection study with the simple herpes virus (HSV-1), amentoflavone inhibited HSV-1 gene and protein expression, inhibited Acyclovirresistant (ACV-resistant) strains infection, reduced the nuclear import of HSV-1, and reduced immediate early gene promoter activity [48], showing great potential as an antiviral compound.

\section{Emodin (Isatis indigotica)}

Emodin is an extract from the Isatis indigotica plant that exerted strong antiviral activity by inhibition of 3CLpro ${ }^{[49]}$. Emodin also blocks the SARS-CoV S / ACE -2 protein interaction and inhibits the adhesion of the virus in the cell surface (Fig. 1) ${ }^{[50]}$. Thus, emodin could prevent SARS-CoV by blocking viral entry and release. Interestingly, emodin increased the survival rate in an animal model of H1N1 infection, reducing edema, viral pulmonary titer, and inflammatory cytokines, and improved pulmonary histopathological changes [51]. Emodin also inhibits influenza $A$ virus and influenza viral pneumonia through the Nuclear factor erythroid 2-related factor 2 (Nrf2), Toll-like receptor 4 (TLR4), p38/ c-Jun NH2-terminal kinases (JNK), and NF-K $\beta$ pathways ${ }^{[51]}$. In 2007 , a study was conducted mapping 312 Chinese herbs supervised by the Taiwanese Committee on
Chinese Medicine and Pharmacy. Three herbs from the Polygonaceae family were observed to inhibit the interaction of the S SARS-CoV and ACE2 protein, Rhizoma Rhei, Radix Polygoni multiflora, and Caulis Polygoni multiflora ${ }^{[50]}$. In this study, emodin, derived from the genus Rheum and Polygonum, significantly blocked the interaction of protein S and ACE2 in a dosedependent manner. Emodin also inhibited the infectivity of pseudotyped retroviruses with protein $S$ for Vero E6 cells ${ }^{[50]}$. The authors suggest that emodin can be considered a potential leading therapeutic agent in the treatment of SARS.

\section{Resveratrol}

Resveratrol (trans-3, 5, 4'-trihydroxystilbene) is a natural derivative of stilbene present in abundance in Vitis vinifera, Polygonum cuspidatum, and Vaccinium macrocarpon. This nutraceutical proved to be efficient in inhibiting coronavirus infection of the Middle East Respiratory Syndrome (MERS-CoV) [52]. Resveratrol has been shown to play a beneficial role in the prevention and progression of chronic diseases related to inflammation, such as diabetes, obesity, cardiovascular disease, neurodegeneration, cancer, and others. In addition, resveratrol has also played an important role in the immune system, interfering in the regulation of immune cells, in the synthesis of pro-inflammatory cytokines, and in gene

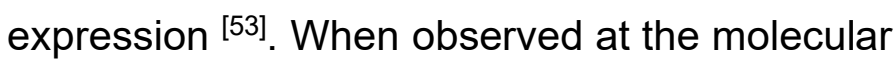
level, resveratrol targets sirtuin, adenosine monophosphate kinase, NF-kB, inflammatory cytokines, antioxidant enzymes, lipid metabolism, mitochondrial biogenesis, angiogenesis, and apoptosis, exerting a large immunoregulatory effect in immune cells by suppressing the tol-like receptor (TLR) and the expression of pro-inflammatory genes [53]. Studies have shown that resveratrol significantly 
inhibited MERS-CoV infection and prolonged cell survival after infection by the virus ${ }^{[54]}$. In this same study, it was also reported that the expression of the nucleocapsid ( $\mathrm{N}$ ) protein essential for MERS-CoV replication decreased after treatment with resveratrol. In addition, resveratrol negatively regulated MERS-CoVinduced apoptosis in vitro ${ }^{[54]}$.

\section{Artemisinin (Artemisia annua)}

Artemisinin is a sesquiterpene lactone with endoperoxide function isolated from the Artemisia annua $L$ plant, widely used as an antimalarial medication [55]. It has also been reported that artemisinin has antibacterial, antiinflammatory, and antiangiogenic activities [56]. However, because of its low solubility and low oral bioavailability, its therapeutic efficacy is not ideal [57]. Some ways of overcoming these obstacles have been devised, such as producing various synthesized analogs of artemisinin, such as dihydroartemisinin and artenusate, which have been evaluated for their potential antimicrobial effect [58]. These compounds exhibited in vitro antiherpes virus, human anticytomegalovirus, human immunodeficiency antivirus, and hepatitis B anti-virus activities [59]. Likewise, the use of techniques such as enveloping artemisinin in a liposome to improve bioavailability has demonstrated great efficiency in the administration of this drug ${ }^{[60]}$. Considering the reported broad-spectrum antiviral potential of artemisinin, several researchers are interested in knowing its effectiveness in combating COVID-19. Scientific studies have systematically evaluated the anti-SARS-CoV-2 activities of nine artemisinin-related compounds in vitro, conducting a drug-addiction time trial to explore their antiviral mode of action, and a pharmacokinetic prediction model established to predict the potential treatment of selected compounds against COVID-19 [61]. The results showed that Arteannuin $B$ had the highest antiSARS-CoV-2 potential, with an effective concentration value (EC50) of $10.28 \pm 1.12 \mu \mathrm{M}$. Other compounds, such as artesunate and dihydroartemisinin, had similar effective EC50 of $12.98 \pm 5.30 \mu \mathrm{M}$ and $13.31 \pm 1.24 \mu \mathrm{M}$, respectively, which could be achieved clinically in plasma after intravenous administration. This research highlighted the anti-SARS-CoV-2 potential of artemisinins and provided the main candidates for research and development of anti-SARS-CoV2 drugs ${ }^{[61]}$.

In the same way, a researcher at the University of Kentucky, in partnership with the University of Berlin, has observed Artemisia annua as an antiviral agent ${ }^{[62]}$. The Max Planck Institute for Colloids and Interfaces (Germany) is working in partnership with ArtemiLife Inc. (USA) to explore the effect of artemisinin obtained from Artemisia annua against SARS-CoV2(MPIKG-2020) [62]. Furthermore, the plant kingdom remains practically unexplored and may have several other bioactive molecules of therapeutic importance still to be discovered in this part of the world.

\section{Licorine (Lycoris Radiata)}

Lycoris radiata is a plant widely distributed in the south of China, Vietnam, and Malaysia, and is used as a folk medicine to treat mastitis, tympanitis, ulcers, and carbuncles in China [63]. In a clinical study, hundreds of natural products were examined, and four extracts of Chinese herbs used in traditional Chinese medicine were found to exhibit anti-SARS-CoV activity in assays based on Vero cells ${ }^{[6]}$. In a clinical study, Li et al. (2005) examined hundreds of natural products, finding that four Chinese herbal extracts used in TCM exhibited anti-SARS-CoV activity in Vero cell-based assays ${ }^{[64]}$. Of the four herbs, Lycoris radiata had the best potency (EC50: $2.4 \pm 0.2 \mu \mathrm{g} / \mathrm{ml}$ ). The results of this study 
demonstrated that these herbs or herbal extracts, The EC50 value $(15.7 \pm 1.2 \mathrm{nM})$ of the viral especially Lycoris radiata, may be good inhibition assay was lower than that of the candidates for antiviral drugs ${ }^{[64]}$. These studies original crude extract, which was expected for a have also led to the identification of licorine as a single active component ${ }^{[65] .}$ potent antiviral compound against SARS-CoV.

Table 2 - Asian Herbs effective concentration values (EC50) in potential antiviral treatment.

\begin{tabular}{|c|c|c|c|}
\hline S. no. & Name of herb & ECso value & References \\
\hline 1 & Arteannuin B & $10,28 \pm 1,12 \mu \mathrm{M}$ & Cao et al. 2020 \\
\hline 2 & Artemisia annua & $34.5 \pm 2.6 \mu \mathrm{g} / \mathrm{ml}$ & Li et al., 2005 \\
\hline 3 & Artesunate & $12.98 \pm 5.30 \mu \mathrm{M}$ & Cao et al. 2020 \\
\hline 4 & Dhydroartemisinin & $13.31 \pm 1.24 \mu \mathrm{M}$ & Cao et al. 2020 \\
\hline 5 & Glycyrrhiza glabra & $300 \mu \mathrm{g} / \mathrm{ml}$ & Cinati et al., 2003 \\
\hline 6 & Lycoris radiata & $2,4 \pm 0.2 \mu \mathrm{g} / \mathrm{ml}$ & Li et al., 2005 \\
\hline 7 & Luteolin & $9.02 \mu \mathrm{M}$ & Yi et al. 2004 \\
\hline 8 & Psoralea corylifolio (Bavachinin) & $38.4 \pm 2.4 \mu \mathrm{M}$ & Kim et al., 2014 \\
\hline 9 & Torreya nucifera (Amentoflavone) & $8.3 \mu \mathrm{M}$ & Ryu et al., 2010 \\
\hline
\end{tabular}

\section{Discussion}

The mortality rate in Mainland China in 2002 by SARS was the lowest when compared to other areas, such as Canada, France, Malaysia, Philippines, Thailand, Hong Kong, Taiwan, Singapore, and Vietnam [64]. China's figures reached just $7 \%$, closely followed by Vietnam, with $8 \%$. All other countries had rates above $10 \%$, with the highest in Malaysia at $40 \%{ }^{[65]}$. Some studies at the time attributed this lower mortality rate in Mainland China and the relatively rapid control of the SARS 2002 outbreak due to the inclusion of herbal formulations from Traditional Chinese Medicine (TCM) in treatment protocols. This lower lethality rate in Beijing, when compared to Hong Kong (17\%) and Singapore $(14 \%)$, for example, can be attributed to the use of a combination of TCM medicinal herbs alongside conventional drugs, while Hong Kong and Singapore used only conventional medicine [66]. This drew the researchers to conclude that an integrative approach could more efficiently control the response to the virus and, consequently, the number of deaths.

In a study by Jia and Gao (2003), the authors reported that at Beijing You-an Hospital, in the SARS pandemic 2003 , the death rate of critically ill patients was $15.4 \%$ when a combination of drugs and herbs was used, and it was $47.7 \%$ when only conventional drugs were applied [67]. 
Likewise, Lau et al. (2005) mentioned that in 2003, 3160 employees at a hospital in Beijing used medicinal plants from TCM as a preventive measure, and within 15 days, none of the consumers of this cocktail contracted SARS COV-1 [68]. Another factor to be observed was both the rarity of side effects and mild adverse events. Although the number of people reported by these authors is quite expansive, a more indepth longitudinal study would need to be prepared for a more plausible conclusion. According to Prasad et al. (2020), all of these results emphasize the need to study more closely the combined effect of plant-based compounds, as well as their isolated extracts and synthetic molecules to bypass the viral load in the host system ${ }^{[23]}$. However, minimal efforts have been invested in this direction so far as to study the synergistic antiviral effect of biomolecules and drugs combination of medicinal herbs ${ }^{[23,27]}$.

Finally, no less important in combating SARS COV and SARS COV-2 is Indian medicine. India has traditional treatment systems that are considered one of the oldest treatments in human history, playing a very important role in global health needs ${ }^{[69]}$. Around 25,000 herbal formulations have been used in folk remedies in India and are still used today [70]. Although specialists in Indian medicine today use about 8,000 different types of herbs, researchers say that western science ignores these treatments in the research and development of modern medicines since their translational potentials are often underestimated [70,71]. Many doctors from both TCM and Indian medicine know that a single herb can contain many phytochemical constituents that work, often alone or need a combination with other phytochemicals to produce the desired pharmacological effect depending on the treatment ${ }^{[72]}$.
Many researchers believe that there are large number of herbal compounds available for medicinal use with the potential to inhibit coronavirus proteins. However, these compounds must be tested, both alone and conjugated against SARS-CoV-2 and evaluated with the cycle-build-testlearn project to assess their effectiveness and side effects. We can take as an example the studies done with glycyrrhizin from Glycyrrhiza glabra when compared to the studies done with Lycoris radiata. Although glycyrrhizin demonstrated good antiviral activity against SARS-CoV in vitro, the EC50 results (300 $\mu \mathrm{g} / \mathrm{ml}$ ) were very high ${ }^{[28]}$. On the other hand, Lycoris radiata showed more promising antiviral activities, with EC50 values of $2.4 \mu \mathrm{g} /$ $\mathrm{ml} \pm 0.2 \mu \mathrm{g} / \mathrm{ml}$. The results of these studies suggest that herbs such as Lycoris radiata may be a good candidate for antiviral drugs [64]. Although the antiviral activity of Lycoris radiata demonstrated in clinical trials is remarkable, the mechanism of how this occurs is still unclear, needing more studies to better understand its mechanism of action.

\section{Conclusion}

Based on the studies presented in this review, we believe that a combination of medicinal herbs could help in combating the SARS-COV-2 pandemic, as well as minimizing the damage caused by the virus. Each phytochemical works in a specific area of metabolism to fight both viral replication (Lycoris radiata) and the reduction of damage caused by the inflammatory (Resveratrol) process presented by COVID-19, as well as cell virus adhesion (Artemisia Annua and Emodin). There are currently no studies on the synergistic action of medicinal plants and their role in human metabolism to aid in controlling the SARS CoV pandemic at this moment. The results presented in this review are promising in the search for prophylactic 
treatment in a viral pandemic as in the case of SARS-VOC-2. However, more clinical trials to validate the processes of effectiveness of both plants and their extracts, as well as the synergy between the plants themselves are needed to validate future treatments against SARS-COV-2.

\section{Reference}

[1] Esakandari $H$, Nabi-afjadi M, Fakkari-afjadi J, Farahmandian N, Miresmaeili S, Bahrein E. A comprehensive review of COVID-19 characteristics. Biol Proced Online. 2020; 22: 19.

[2] Yuen KS, Ye Z.W, Fung SY, Chan CP, Jin DY. SARS-CoV-2 and COVID-19: The most important research questions. Cell Biosci. 2020; 10()$: 40$.

[3] Zabetakis I, Lordan R., Norton C., Tsoupras A. COVID-19: The Inflammation Link and the Role of Nutrition in Potential Mitigation. Nutrients 2020, 12(5), 1466.

[4] Ioannidis JPA, Axfors C, Contopoulos-loannidis DG. Population-level COVID-19 mortality risk for non-elderly individuals overall and for nonelderly individuals without underlying diseases in pandemic epicenters. Environ Res. 2020 Sep; 188: 109890.

[5] Gelman R, Bayatra A, Kessler A, Schwartz A, Ilan Y. Targeting SARS-CoV-2 receptors as a means for reducing infectivity and improving antiviral and immune response: an algorithmbased method for overcoming resistance to antiviral agents. Emerg Microbes Infect. 2020; 9(1): 1397- 1406.

[6] Zhou D, Duyvesteyn HME, Huang KA. Structural basis for the neutralization of SARS-CoV-2 by an antibody from a convalescent patient. Nature Structural \& Molecular Biology (2020).

[7] Sever $P$ and Johnston SL. The ReninAngiotensin system and SARS-CoV-2 infection: A role for the ACE2 receptor? Journal of the Renin-AngiotensinAldosterone System. AprilJune 2020: 1-2.
[8] Turner AJ, Hiscox JA and Hooper NM. ACE2: from vasopeptidase to SARS virus receptor. TRENDS in Pharmacological Sciences Vol.25 No.6 June 2004

[9] Banua N, Panikarb SS, Lealc LR, Leald AR. Protective role of ACE2 and its downregulation in SARS-CoV-2 infection leading to Macrophage Activation Syndrome: Therapeutic implications. Life Sciences. Volume 256, 1 September 2020, 117905.

[10] Garg S, Kim L, Whitaker M, O'Halloran A, Cummings $\mathrm{C}$, et al. Hospitalization Rates and Characteristics of Patients Hospitalized with Laboratory-Confirmed Coronavirus Disease 2019 - COVID-NET, 14 States, March 1-30, 2020. Weekly / April 17, 2020 / 69(15);458-464.

[11] Ziegler CGK, Allon SJ, Nyquist SK, Mbano IM, Vincent N Miao VN, et al. SARS-CoV-2 Receptor ACE2 Is an Interferon-Stimulated Gene in Human Airway Epithelial Cells and Is Detected in Specific Cell Subsets across Tissues. Cell. 2020 May 28;181(5):1016-1035.e19.

[12] Satarker S, Nampoothiri M. Structural Proteins in Severe Acute Respiratory Syndrome Coronavirus-2. Archives of Medical Research Volume 51, Issue 6, August 2020, Pages 482491.

[13] Wu XD, Shang B, Yang RF, Yu H, Ma ZH, et al. The spike protein of severe acute respiratory syndrome (SARS) is cleaved in virus infected Vero-E6 cells. Cell Research volume 14, pages400-406(2004).

[14] Hoffmann M, Kleine-Weber H, Schroeder S, Krüger N, Herrler T. et al. SARS-CoV-2 Cell Entry Depends on ACE2 and TMPRSS2 and Is Blocked by a Clinically Proven Protease Inhibitor. Cell. 2020 Apr 16;181(2):271-280.e8.

[15] Li W, Moore MJ, Vasilieva N, Sui J, Wong SK, et al. Angiotensin-converting enzyme 2 is a functional receptor for the SARS coronavirus. Nature volume 426, pages450-454(2003). 
[16] Hamilton BS, Gludish DWJ, Whittake GR. Cleavage Activation of the Human-Adapted Influenza Virus Subtypes by Matriptase Reveals both Subtype and Strain Specificities. J Virol. 2012 Oct; 86(19): 10579-10586.

[17] Munster VJ, Feldmann F, Williamson BN, van Doremalen N, Pérez-Pérez L, et al. Respiratory disease in rhesus macaques inoculated with SARS-CoV-2. Nature volume 585, pages268272(2020).

[18] Ding Y, He L, Zhang Q, Huang Z, Che X, et al. Organ distribution of severe acute respiratory syndrome (SARS) associated coronavirus (SARS-CoV) in SARS patients: implications for pathogenesis and virus transmission pathways. J Pathol. 2004 Jun;203(2):622-30.

[19] Hamming I, Timens W, Bulthuis MLC, Lely AT, Navis GJ. Tissue distribution of ACE2 protein, the functional receptor for SARS coronavirus. A first step in understanding SARS pathogenesis. J Pathol. 2004 Jun;203(2):631-7.

[20] Cheong DHJ, Tan DWS, Wong FWS, Tran T. Anti-malarial drug, artemisinin and its derivatives for the treatment of respiratory diseases. Pharmacol Res. 2020 Aug;158:104901.

[21] Sharifkashani S, Bafrani MA, Khaboushan AS, Pirzadeh M, Kheirandish $A$, et al. Angiotensinconverting enzyme 2 (ACE2) receptor and SARS-CoV-2: Potential therapeutic targeting. European Journal of Pharmacology. Volume 884, 5 October 2020, 173455.

[22] Li Q, Wang H, Li X, Zheng Y, Wei Y, et al. The role played by traditional Chinese medicine in preventing and treating COVID-19 in China. Frontiers of Medicine (2020).

[23] Chen Z, Nakamura T. Statistical evidence for the usefulness of Chinese medicine in the treatment of SARS. Phyther Res, 2004,18:592-594.

[24] O'Connor SE. Engineering of Secondary Metabolism. Annu Rev Genet. 2015;49:71-94.

[25] Thomford NE, Dzobo K, Chopera D, Wonkam A,
Skelton $M$, et al. Pharmacogenomics Implications of Using Herbal Medicinal Plants on African Populations in Health Transition. Pharmaceuticals 2015, 8(3), 637-663.

[26] Gulati K, Rai N, Chaudhary S, Ray A. Nutraceuticals in Respiratory Disorders. Nutraceuticals. 2016, Pages 75-86.

[27] Wang L, Yang R, Yuan B, Liu Y, Liu C. The antiviral and antimicrobial activities of licorice, a widely-used Chinese herb. Acta Pharm Sin B. 2015 Jul; 5(4): 310-315.

[28] Cinatl J, Morgenstern B, Bauer G, Chandra P, Rabenau $H$, et al. Glycyrrhizin, an active component of liquorice roots, and replication of SARS-associated coronavirus. Lancet. 2003 Jun 14;361(9374):2045-6.

[29] Hoever G, Baltina L, Michaelis M, Kondratenko $\mathrm{R}$, Baltina L, et al. Antiviral activity of glycyrrhizic acid derivatives against SARS-coronavirus. J Med Chem. 2005 Feb 24;48(4):1256-9.

[30] Fiore C, Eisenhut M, Krausse R, Ragazzi E, Pellati D, et al. Antiviral effects of Glycyrrhiza species. Phytother Res. 2008 Feb;22(2):141-8.

[31] Ashfaq UA, Masoud MS, Nawaz Z, Riazuddin S. Glycyrrhizin as antiviral agent against Hepatitis C Virus. J TransI Med. 2011; 9: 112.

[32] Ito M, Sato A, Hirabayashi K, Tanabe F, Shigeta $S$, et al. Mechanism of inhibitory effect of glycyrrhizin on replication of human immunodeficiency virus (HIV). Antiviral Res. 1988 Dec 11;10(6):289-98.

[33] Zhang H, Song Y, Zhang Z. Glycyrrhizin administration ameliorates coxsackievirus B3induced myocarditis in mice. Am J Med Sci. 2012 Sep;344(3):206-10.

[34] Soufy H, Yassein S, Ahmed AR, Khodier MH, Kutkat MA et al. Antiviral and immune stimulant activities of glycyrrhizin against duck hepatitis virus. Afr J Tradit Complement Altern Med. 2012 Apr 2;9(3):389-95.

[35] Wang J, Chen X, Wang W, Zhang Y, Yang Z, et 
al. Glycyrrhizic acid as the antiviral component of Glycyrrhiza uralensis Fisch. against coxsackievirus A16 and enterovirus 71 of hand foot and mouth disease. J Ethnopharmacol. 2013 May 2; 147(1): 114-121.

[36] Yu M, Lee J, Lee JM, Kim Y. Identification of myricetin and scutellarein as novel chemical inhibitors of the SARS coronavirus helicase, nsP13. April 2012. Bioorganic \& medicinal chemistry letters 22(12):4049-54.

[37] Sirion U, Kasemsuk T, Suksen K, Piyachaturawat P. Bioorganic \& Medicinal Chemistry Letters 22 (2012) 49-52. January 2016.

[38] Achan J, Talisuna AO, Erhart A, Yeka A, Tibenderana JK, et al. Quinine, an old antimalarial drug in a modern world: role in the treatment of malaria. Malar J. 2011 May 24;10:144.

[39] De Leo M, Braca A, Sanogo R, Cardile V, DeTommasi N, Russo A. Antiproliferative activity of Pteleopsis suberosa leaf extract and its flavonoid components in human prostate carcinoma cells. Planta Med. 2006 Jun; 72(7):604-10.

[40] Kong NN, Fang ST, Wang JH, Wang ZH, Xia CH. Two new flavonoid glycosides from the halophyte Limonium franchetii. J Asian Nat Prod Res. 2014; 16(4):370-5.

[41] Wang L, Yang R, Yuan B, Liu Y, Liu C. The antiviral and antimicrobial activities of licorice, a widely-used Chinese herb. Acta Pharm Sin B. $2015 \mathrm{Jul} ;$ 5(4): 310-315.

[42] Ghannad MS, Mohammadi A, Safiallahy S, Faradmal J, Azizi M, et al. The Effect of Aqueous Extract of Glycyrrhiza glabra on Herpes Simplex Virus 1. Jundishapur J Microbiol. 2014 Jul; 7(7): e11616.

[43] Michaelis M, Geiler J, Naczk P, Sithisarn P, Leutz A, et al. Glycyrrhizin Exerts Antioxidative Effects in H5N1 Influenza A Virus-Infected Cells and
Inhibits Virus Replication and Prolnflammatory Gene Expression. PLoS One. 2011; 6(5): e19705.

[44] Gautret P, Lagier J, Parola P, Hoang VT, Meddeb $\mathrm{L}$, et al. Hydroxychloroquine and azithromycin as a treatment of COVID-19: results of an openlabel non-randomized clinical trial. Int $\mathrm{J}$ Antimicrob Agents. 2020 Jul;56(1):105949.

[45] Große M, Ruetalo N, Businger R, Rheber S, Setz C. Evidence That Quinine Exhibits Antiviral Activity against SARS-CoV-2 Infection In Vitro. life sciences. Virology. 202007.0102.v1.

[46] Ryu YB, Jeong HJ, Kim JH, Kim YM, Park J, et al. Biflavonoids from Torreya nucifera displaying SARS-CoV 3CLpro inhibition. Bioorganic \& Medicinal Chemistry. Volume 18, Issue 22, 15 November 2010, Pages 7940-7947.

[47] Kao RY, Tsui WH, Lee TS, Tanner JA, Watt RM. Identification of novel small-molecule inhibitors of severe acute respiratory syndromeassociated coronavirus by chemical genetics. Chem Biol. 2004 Sep; 11(9):1293-9.

[48] Li F, Song $X$, Su G, Wang $Y$, Wang $Z$ et al. Amentoflavone Inhibits HSV-1 and ACVResistant Strain Infection by Suppressing Viral Early Infection. Viruses. 2019 May; 11(5): 466.

[49] Lin C, Tsai F, Tsai C, Lai C, Wan L, Ho T et al. Anti-SARS coronavirus 3C-like protease effects of Isatis indigotica root and plant-derived phenolic compounds. Antiviral Res. 2005 Oct;68(1):36- 42 .

[50] Ho T, Wu S, Chen J, Hsiang C. Emodin blocks the SARS coronavirus spike protein and angiotensin-converting enzyme 2 interaction. Antivir Res. 2007;74(2):92-101.

[51] Dai J, Wang Q, Su Y. Emodin inhibition of influenza $A$ virus replication and influenza viral pneumonia via the Nrf2, TLR4, p38/JNK and NFkappaB pathways. Molecules. 2017;22(10).

[52] Lin S, Ho C, Chuo W, Li S, Tony T, et al. Effective inhibition of MERS-CoV infection by esveratrol. 
BMC Infect Dis. 2017 Feb 13;17(1):144.

[53] Malaguarnera L. Influence of Resveratrol on the Immune Response. Nutrients. 2019 May; 11(5): 946.

[54] Lin S, Ho C, Chuo W, Li S, Wang TT. Effective inhibition of MERS-CoV infection by resveratrol. BMC Infect Dis. 2017; 17: 144.

[55] Obeid S, Alen J, Nguyen VH, Pham VC, Meuleman P, et al. Artemisinin Analogues as Potent Inhibitors of In Vitro Hepatitis C Virus Replication. PLoS One. 2013; 8(12): e81783.

[56] Posner GH, Chang W, Hess L, Woodard L, Sinishtaj S, et al. Malaria-infected mice are cured by oral administration of new artemisinin derivatives. J Med Chem. 2008 Feb 28; 51(4):1035-42.

[57] Messori L, Gabbiani C, Casini A, Siragusa M, Vincieri $\mathrm{FF}$, et al. The reaction of artemisinins with hemoglobin: a unified picture. Bioorg Med Chem. 2006 May 1; 14(9):2972-7.

[58] Meshnick SR. Artemisinin: mechanisms of action, resistance and toxicity. Int J Parasitol. 2002 Dec 4; 32(13):1655-60.

[59] Efferth T, Marschall M, Wang X, Huong SM, Hauber I, et al. Antiviral activity of artesunate towards wild-type, recombinant, and ganciclovirresistant human cytomegaloviruses. J Mol Med (Berl). 2002 Apr; 80(4):233-42.

[60] Want MY, Islammudin M, Chouhan G, Ozbak HA, Hemeg HA, et al. Nanoliposomal artemisinin for the treatment of murine visceral leishmaniasis. Int J Nanomedicine. 2017; 12: 2189-2204.

[61] Cao R, Hu H, Li Y, Wang X, Xu M, et al. AntiSARS-CoV-2 Potential of Artemisinins In Vitro. ACS Infect Dis. 2020 Jul 31: acsinfecdis.0c00522.

[62] Gilmore K, Osterrieder, K, Seeberger $\mathrm{PH}$. Extracts of the plant $A$. annua are active against SARSCoV-2. Cooperation between scientists from the Max Planck Institute, University of
Kentucky and Freie Universität Berlin. № 107/2020 from Jun 24, 2020.

[63] Prasad A, Muthamilarasan M, Prasad M. Synergistic antiviral effects against SARS-CoV-2 by plant-based molecules. Plant Cell Rep. 2020 Sep;39(9):1109-1114.

[64] Sheng-Dian H, Yu Z , Hong-Ping HE , Shi-Fei L, Gui-Hua T, et al. A new Amaryllidaceae alkaloid from the bulbs of Lycoris radiata. Chinese Journal of Natural Medicines 2013, 11(4): 0406 0410.

[65] Li S, Chen C, Zhang H, Guo H, Wang H, et al. Identification of natural compounds with antiviral activities against SARS-associated coronavirus. Antiviral Res. 2005 Jul; 67(1): 18-23.

[66] Fuzimotoa $A D$, and Isidoro $C$. The antiviral and coronavirus-host protein pathways inhibiting properties of herbs and natural compounds Additional weapons in the fight against the COVID19 pandemic? J Tradit Complement Med. 2020 Jul; 10(4): 405-419.

[67] Chen F., Chan K., Jiang Y. In vitro susceptibility of 10 clinical isolates of SARS coronavirus to selected antiviral compounds. J Clin Virol. 2004;31(1):69-75.

[68] Jia W, Gao W. Is traditional Chinese medicine useful in the treatment of SARS? Phytother Res. 2003 Aug;17(7):840-1.

[69] Ravishankar B., Shukla V. Indian systems of medicine: a brief profile. Afr. J. Trad. Complement. Altern. Med. 2007;4:319-337.

[70] Pundarikakshudu K., Kanaki N.S. Analysis and regulation of traditional Indian medicines (TIM) J. AOAC Int. 2019;102:977-978.

[71] Yuan H., Ma Q., Ye L., Piao G. The traditional medicine and modern medicine from natural products. Molecules. 2016;21:559.

[72] Parasuraman S, Thing GS, Dhanaraj SA. Polyherbal formulation: concept of ayurveda. Pharmacogn. Rev. 2014;8:73. 